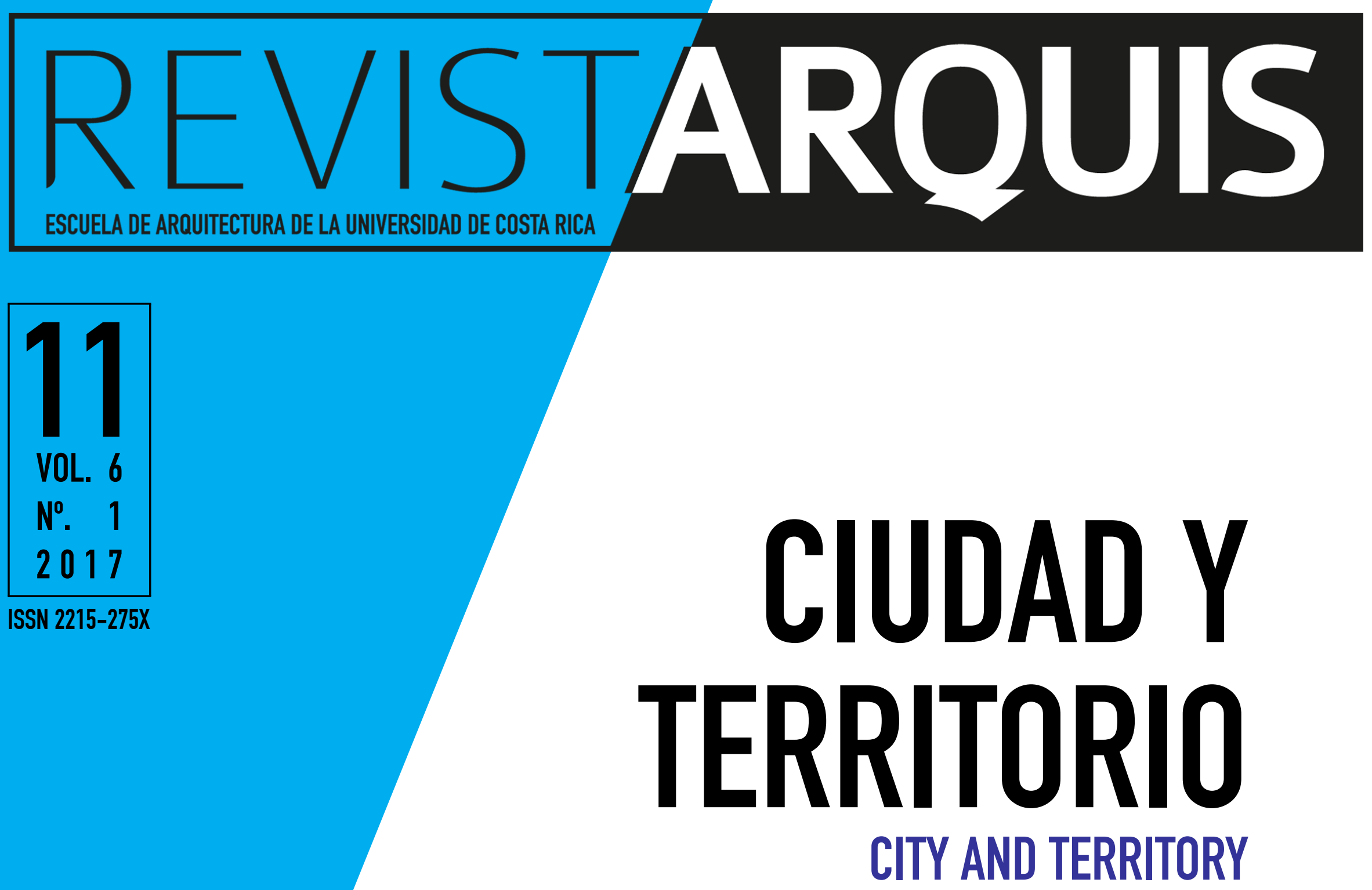

1_ ¿Gentrificación latinoamericana? Apuntes para su discusión Luis Alberto Salinas Arreortua Ensayo | 1-10

2_Los estudios culturales y la construcción social del patrimonio cultural Rosa Elena Malavassi Aguilar

Investigación | 11-19

3_ Un centro cívico o el réquiem del patrimonio urbano costarricense Marcela Muñoz Muñoz

Ensayo | 20-28

4_Viabilidad para la implementación de estrategias de renovación urbana en Costa Rica

Dania Chavarría Núñez

Ensayo | 29-38

5_Estado actual y perspectivas de la legislación urbana en Costa Rica Jessica Martínez Porras

Reflexión | 39-47 

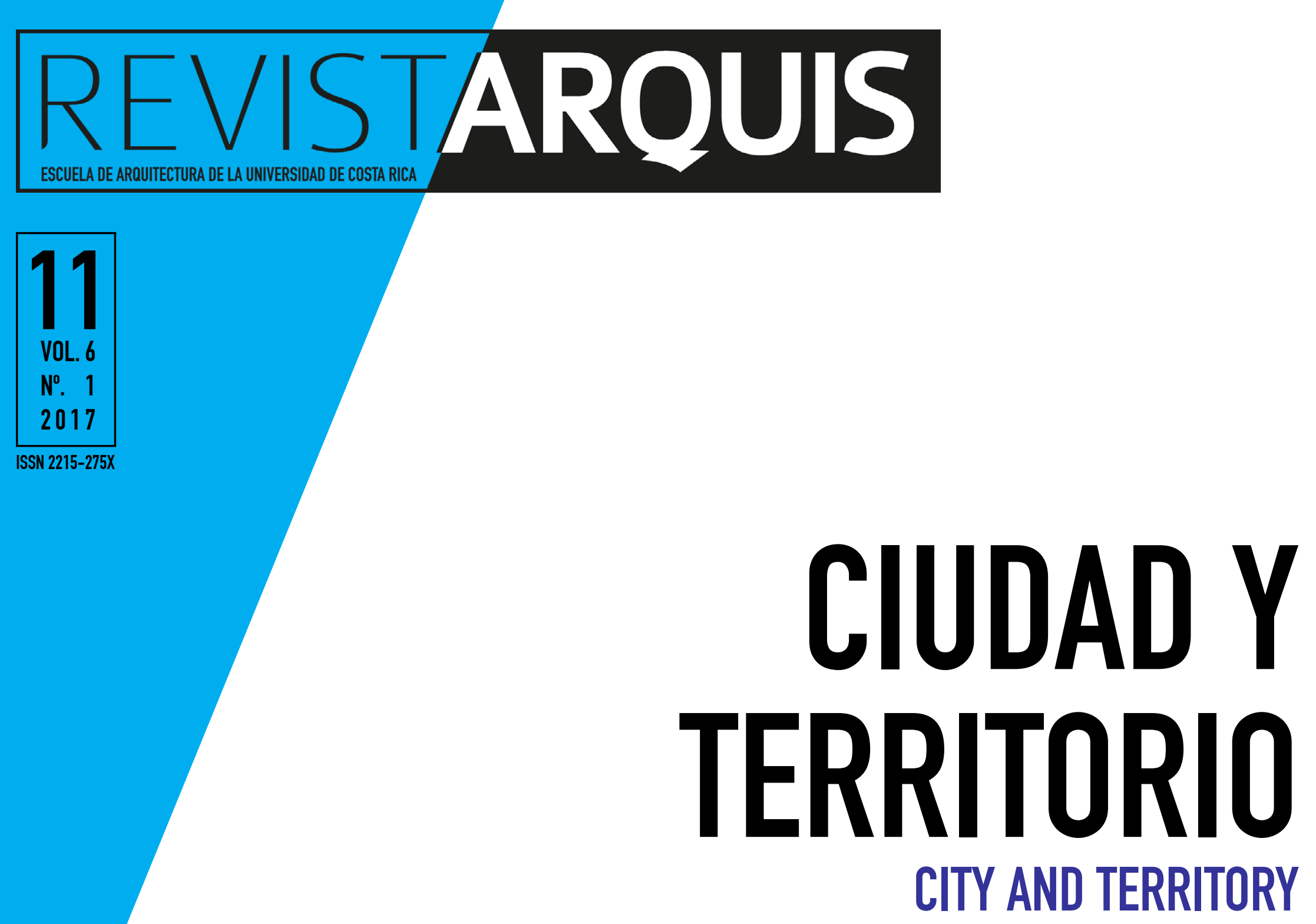

1_ ¿Gentrificación latinoamericana? Apuntes para su discusión Luis Alberto Salinas Arreortua

Ensayo | $1-10$

\footnotetext{
2_Los estudios culturales y la construcción social del patrimonio cultural Rosa Elena Malavassi Aguilar

Investigación | 11-19

3_Un centro cívico o el réquiem del patrimonio urbano costarricense Marcela Muñoz Muñoz

Ensayo | 20-28
4_Viabilidad para la implementación de estrategias de renovación urbana en Costa Rica
Dania Chavarría Núñez
Ensayo | 29-38
5_Estado actual y perspectivas de la legislación urbana en Costa Rica Jessica Martínez Porras
Reflexión | 39-47




\title{
¿Gentrificación latinoamericana? Apuntes para su discusión
}

\author{
Luis Alberto Salinas Arreortua
}

\section{Resumen}

\section{Ensayo}

Invitado internacional

email: Isalinas@igg.unam.mx

Recibido: 15 de diciembre 2016 Aceptado: 31 de marzo 2017

\section{Luis Alberto Salinas Arreortua}

Licenciado, Maestro y Doctor en Geografía por la Universidad Nacional Autónoma de México. Ha realizado diversas estancias de investigación, entre ellas, una posdoctoral en el departamento de Ciencia Política y Relaciones Internacionales de la Universidad Autónoma de Madrid, España. Investigador Asociado "C" en el Instituto de Geografia de la UNAM. Miembro del Sistema Nacional de Investigadores, CONACyT, México.
A pesar que el concepto de gentrificación fue utilizado en la década de los sesenta, es hasta las teorías desarrolladas por Smith y Ley, a finales de los setenta, que comienzan a desarrollarse diversos trabajos empíricos en el mundo anglosajón. Mientras que en América Latina, los trabajos empíricos comienzan a producirse, de manera destacada, hacia la primera década del siglo XXI. Se discuten diversos argumentos que explican la tardía producción de trabajos empíricos sobre casos de gentrificación en ciudades latinoamericanas, exponiendo las principales críticas que se han producido acerca del uso de este concepto, así como del desalojo de una perspectiva crítica, dando como resultado propuestas contrarias al origen del concepto. Por último, se retoman los rasgos que caracterizan los procesos de gentrificación en esta región.

Palabras clave: América Latina; gentrificación; perspectiva crítica; uso del concepto.

\section{Latin American gentrification? Notes for discussion}

\begin{abstract}
Although the concept of gentrification was used in the 1960s, it is even the theories developed by Smith and Ley in the late 1970s that various empirical works in the AngloSaxon world are beginning to develop. While in Latin America, the empirical work begins to take place, in a remarkable way, towards the first decade of the 21 st century. Several arguments are discussed that explain the late production of empirical work on cases of gentrification in Latin American cities, exposing the main criticisms that have been made about the use of this concept, as well as the eviction of a critical perspective, resulting in proposals that are contrary to the origin of the concept. Finally, the traits that characterize the processes of gentrification in this region are taken.
\end{abstract}

Keywords: Latin America; gentrification; critical perspective; use of concept 


\section{Introducción}

A

pesar que el concepto de gentrificación fue utilizado hacia el año de 1964, es hasta las teorías desarrolladas por Neil Smith y David Ley, a finales de los setenta, que comienzan a desarrollarse diversos trabajos empíricos, basados en la teoría de la oferta como en la demanda, los cuales se dedican en su gran mayoría a casos de ciudades británicas, norteamericanas y de Europa occidental, principalmente. Mientras que en regiones como América Latina, los trabajos empíricos comienzan a producirse, de manera destacada, hacia la primera década del siglo XXI. En el presente texto se tratan dos objetivos principales; 1) contribuir en la discusión sobre los argumentos que explican la tardía producción de trabajos empíricos sobre casos de gentrificación en ciudades latinoamericanas, exponiendo las principales críticas que se han producido acerca del manejo de este concepto, así como del desalojo de una perspectiva crítica, dando como resultado propuestas contrarias al origen del concepto; 2) analizar los rasgos que caracterizan -dentro de esta reciente producción académica- los procesos de gentrificación en nuestras latitudes.

Como primer paso, se retoma la definición clásica de gentrificación, para argumentar cómo ha evolucionado la concepción de este proceso, permitiendo explicar transformaciones que se refieren, no solamente al uso de suelo habitacional y a procesos de renovación, sino también a transformaciones, por ejemplo, de uso de suelo comercial. Sin embargo, resulta importante manejar con precaución el uso del concepto y delimitarlo de manera que no se haga un uso indiscriminado de dicho concepto. Considerando la evolución conceptual y el debate posterior suscitado a partir de las dos posiciones teóricas que explican el proceso de gentrificación, se argumenta, por un lado, que por la connotación crítica del concepto, en América Latina se prefiere utilizar diversos términos como "recuperación", "rehabilitación", "ennoblecimiento" y "recualificación", sobre todo en discursos oficiales y en algunos casos incluso en la academia. Por otro lado, sin embargo, hay un uso indiscriminado del concepto, pues se ha convertido en un concepto de "moda", el cual suele utilizarse para nombrar diversas transformaciones urbanas en áreas centrales, e incluso se ha tergiversado su definición al extremo de despojarle de la connotación crítica del mismo.

En segundo lugar, se retoman las discusiones recientes del proceso de gentrificación y las tendencias principales en casos de ciudades latinoamericanas. Se destaca el papel de las autoridades locales en la gestión urbana de tipo "empresarialista", en la cual, mediante distintas estrategias de participación público - privado, en un contexto de políticas urbanas neoliberales, se crean espacios adecuados para la reproducción del capital, razón por la cual, una de las principales características de la gentrificación en ciudades latinoamericanas son mediante las políticas implementadas por los gobiernos locales.

\section{Gentrificación como proceso de transformación urbana}

Este trabajo presenta resultados parciales del proyecto de investigación titulado "Política de vivienda de interés social y mercado formal de suelo urbano en la Zona Metropolitana del Valle de México", CONACyT - 247398; y del proyecto: "Gobiernos metropolitanos y política de vivienda en periferias urbanas. El caso de la ZMVM", PAPIIT IA300416, los cuales se desarrollan en el Instituto de Geografía, UNAM.
Hay un consenso que el concepto fue originado por Ruth Glass en 1964 para describir un proceso de cambio social en un barrio de la ciudad de Londres (ver Zukin, 1987; Smith, 1996; Van Weesep, 1994; García, 2001; Slater, 2006; Lees, et. al., 2008; Herzer, 2008; Rérat, et. al., 2010). La definición propuesta por Glass, hacía alusión a un proceso a través del cual un barrio habitado por población de bajos ingresos es ocupado y modificado por población de clase media - alta, quienes a su vez, ya sea por cuenta propia o por inversión privada (agentes inmobiliarios), renuevan las viviendas. De esta manera, son tres los elementos esenciales para hablar de un proceso de gentrificación clásica (Lees, et. al., 2008, p.10); llegada de población de mayores ingresos, desplazamiento de población y reinversión económica en viviendas.

Además de estos tres elementos que definen un proceso de gentrificación, Ruth Glass, como socióloga marxista, insistía que las transformaciones urbanas sería pertinente analizarlas a partir de la lucha de clases. De esta manera, el proceso de gentrificación de un barrio hace referencia a un problema social y/o de clase (Slater, 2006 y 2008). Este 
es un elemento esencial de la definición, el cual nos permitirá establecer delimitaciones conceptuales para los debates actuales acerca de las mutaciones del proceso.

Por lo expuesto anteriormente, resulta necesario para hablar de un proceso de gentrificación, la connotación crítica, la cual hace referencia a un problema social o de clase que se presenta en la producción del espacio urbano. Este problema social, se hace evidente con la llegada de población de mayores ingresos a la población que existía originalmente, quienes resultan ser desplazados por cuya condición socioeconómica no les permite quedarse en los barrios transformados que han tenido, por lo regular, inversión económica pública o privada, lo que ha resultado en incremento de precios de inmuebles y servicios diversos. Estas características serán esenciales para hablar de un proceso de gentrificación, de manera que las transformaciones pueden darse no solamente sobre uso de suelo habitacional, razón por la cual se han desarrollado investigaciones que versan sobre gentrificación comercial (González y Waley, 2012; Bridge y Dowling, 2001; Romero y Lara, 2015; Salinas, 2015) y gentrificación productiva (Dot; Casellas y Pallares-Bar, 2010; Boixader, 2004; Guillamón, 2003).

Para explicar de mejor manera las transformaciones recientes del proceso de gentrificación, primero se retoma la discusión sobre las dos posturas teóricas que han intentado explicar las causas del proceso a partir de la oferta y la demanda.

\section{Debate en torno al proceso de gentrificación}

Los procesos de transformación urbana en el cual implica inversión de capital, desplazamiento de población y llegada de población de mayores ingresos, se han producido desde la expansión de las ciudades durante el desarrollo industrial. Engels ponía el acento en la transformación de barrios obreros en ciudades inglesas. En Paris, son conocidas las transformaciones realizadas por el Barón de Haussman. Mientras que en Nueva York, hacia mediados del siglo XX, tuvo sus grandes transformaciones con Robert Moses. Sin embargo, los estudios sobre la gentrificación comenzaron a presentarse en ciudades de América del Norte y de Europa Occidental desde el último cuarto del siglo XX, produciéndose su propagación tanto del fenómeno en sí, como de los estudios al respecto.

El énfasis que se le ha dado a la explicación del proceso se relaciona con la reorganización económica mundial de acumulación del capital, de manera particular, a la implementación del modelo neoliberal. Aunque, como bien se ha mencionado, tanto el origen del concepto como diversas transformaciones urbanas que podrían denominarse como gentrificación, se han producido antes de la imposición del modelo neoliberal.

A diferencia de momentos anteriores, con el neoliberalismo las características se han diversificado y las consecuencias se han agudizado. Las transformaciones urbanas se relacionan con la terciarización de la economía, flexibilidad laboral, crecimiento y concentración de trabajadores del sector servicios (cuello blanco) sobre trabajadores del sector industrial (cuello azul) en los centros de las grandes ciudades, libre circulación de capital y estímulos fiscales por parte de las autoridades locales a la inversión privada. Esto es considerado en las dos propuestas teóricas que explican los orígenes de la gentrificación, a partir del análisis de la oferta y de la demanda. Dichas posturas teóricas generaron una fuerte discusión en el ámbito académico.

David Ley, en la conferencia Anual de Nueva Orleans en 1978, presentó un trabajo titulado "Inner city resurgence units societal context", en el cual argumenta que la gentrificación deriva de procesos recíprocos de reestructuracióneconómica, sociocultural y demográfica, para cuyos casos de estudio abordó ciudades canadienses.

Para Ley, uno de sus principales argumentos tiene que ver con los cambios socioculturales (los cuales mantiene presente en sus estudios posteriores: ver Ley, 1980, 1994 y 2003). Dichos cambios socioculturales están estrechamente vinculados a la reestructuración del empleo, al incrementar el porcentaje del empleo calificado (trabajadores de "cuello blanco") y mermando los puestos de trabajo de empleados no calificados (trabajadores de "cuello azul"), lo que se presenta como una tendencia en los centros urbanos de las 
grandes ciudades (Ley, 1994).

La concentración de un sector de la población con puestos de trabajo de gestión, administración, profesionales y de campos técnicos -el denominado cuaternario o sector de servicios avanzados- constituyen la "nueva clase media" (Ley, 1994), o la mal Ilamada "clase creativa" (Florida, 2010), quienes tienen los ingresos económicos para instalarse en áreas urbanas que ofrecen diversas cualidades: espacios públicos, inmuebles con valor arquitectónico e histórico, barrios céntricos con actividad cultural -museos, teatros, cines, universidades-, y sitios que ofrecen diversos servicios. Estos espacios de la ciudad van adquiriendo interés, no sólo por el hecho de encontrarse cerca de sus lugares de trabajo, sino porque además forma parte de un "estilo de vida urbano." (Ley, 1994).

Esta nueva clase media va emprendiendo el proceso de gentrificación en el centro de las ciudades, en la medida en que se instalan en barrios revalorizados y, posteriormente, se extiende a una creciente dinámica económica, ya sea por parte de inversión pública (en la mejora en espacios públicos, alumbrado y seguridad pública, desalojo del comercio ambulante y gente que vive en la calle) y/o privada (inversión inmobiliaria y creciente actividad comercial).

Esta propuesta, que explica el origen del proceso de gentrificación a partir de la demanda, en la medida en que la nueva clase media es quien encabeza el proceso de transformación en los centros de las ciudades, no deja de lado los aspectos de la oferta como se ha llegado a mal interpretar.

Por otra parte, considerada como una contestación a esta teoría, Neil Smith publica en 1979 "Toward a theory of gentrification; a back to the city movement by capital not people", en la cual establece que el creciente interés que existe por las áreas centrales de las ciudades está dirigido por factores económicos -cuyo análisis lo realiza principalmente en Nueva York-. Dicho argumento lo desarrolla en su propuesta de rent-gap, que la trabaja como una hipótesis para la explicación de la gentrificación. "La rent-gap es la disparidad entre el nivel de la renta del suelo potencial y la actual renta del suelo capitalizada bajo el presente uso de suelo" (Smith, 1996, p.67). Asimismo, continúa "La gentrificación ocurre cuando la diferencia es suficientemente alta y los desarrolladores pueden adquirir estructuras baratas, pueden pagar los costos de la construcción y las ganancias de la rehabilitación, pueden pagar intereses de hipotecas y préstamos de construcción, y pueden vender el producto terminado a un precio satisfactorio para el desarrollador." (Smith, 1996, p.68). Razón por la cual, el elemento central que explica el proceso de gentrificación, para Smith, es la dinámica económica, en la cual se busca analizar las condiciones propicias para invertir capital. De esta manera, la oferta va conduciendo el proceso de gentrificación, de modo que el factor económico es preponderante sobre los factores culturales, pero al igual que la propuesta de Ley, Smith toma en cuenta los aspectos socioculturales.

Por su parte, Hamnett (1991) define la gentrificación como un fenómeno simultáneamente físico, económico, social y cultural, pues dependerá de la combinación de factores para que se produzca un proceso de gentrificación y no solamente de uno solo, sea el cultural o el económico. De esta manera, si bien es cierto son dos posturas claramente diferenciadas, ninguna de ellas son excluyentes, pero cada una por su parte son insuficientes para explicar el proceso de gentrificación. Lo que debe quedar claro, más allá de las características que originan dicho proceso (pues éste dependerá de las características locales de cada caso), será considerar los elementos esenciales que permiten definir las transformaciones urbanas como gentrificación. De lo contrario, se pierde la connotación crítica, lo cual podría ser, en algunos casos, derivado de una intención política.

\section{Perspectiva crítica, evasión y mal interpretación del concepto}

La evolución del uso del concepto implica considerar los elementos esenciales que definen dicho proceso. La connotación de clase, evidenciada con la llegada de población de mayores ingresos y su consecuente desplazamiento de población de 
menores recursos, serán los elementos que definan las transformaciones urbanas como gentrificación. Recientemente se ha criticado que los procesos actuales de gentrificación no responden a la "definición clásica" propuesta por Glass, razón por la cual no debería usarse el concepto. De esta manera, es muy común encontrarse con diversos artículos académicos en los cuales se utilizan conceptos como "revitalización", "recuperación", "regeneración", "rehabilitación", "renovación", en muchos de los cuales se hace referencia a problemas sociales o de clase social que bien pueden definirse como gentrificación, pero como continúa siendo una mala palabra (Smith, 1996) para el discurso oficial, suele ser común evadir su utilización, con el argumento - intencionado o no - que no existe un proceso tal y como fue definido por Ruth Glass.

Otra crítica hacia el uso del concepto recae en su metodología. Se ha intentado establecer que la ausencia de datos cuantitativos, en diversos casos de estudio, no permite argumentar que las transformaciones sean consideradas como gentrificación. También existe la postura que establece que el uso del concepto de gentrificación, más que explicar procesos urbanos en ciudades latinoamericanas, es el resultado de la importación de conceptos originados en los países centrales (Jaramillo, 2006), en el cual se intenta amoldar las realidades latinoamericanas a los cuerpos conceptuales, hasta considerarlo como un aspecto neocolonial del conocimiento (Delgadillo, 2013).

Más allá de las razones por las cuales no se venía usando el concepto en ciudades latinoamericanas, y que a partir de principios del siglo XXI hay una propagación del concepto en estas latitudes, es preocupante que se esté tergiversando su definición y se llegue, incluso, a considerar la gentrificación como un resultado positivo, argumentando la existencia de un estado saludable del mercado; pues el mercado es siempre entendido como la solución, no un problema (Lees, et. al., 2008, p.165). De esta manera, por supuesto, la gentrificación puede ser positiva para los gentrificadores, los gobernantes de la ciudad y, particularmente, los dueños del capital. Sin tomar en cuenta que la gentrificación "fue diseñado para capturar el desafío de la expresión de la desigualdad de clase en los barrios" (Slater, 2008, p.216).

En este contexto, se ha desarrollado la llamada gentrificación positiva, la cual establece como argumento central que la gentrificación puede generar tanto consecuencias negativas como positivas. La consecuencia negativa es el desplazamiento de población. La consecuencia positiva es la revitalización de las colonias populares deterioradas (Sabatini et al., 2008.) Si no se da el desplazamiento de población, se destaca que existen consecuencias positivas: inversión económica, generación de empleo, mejoramiento de la infraestructura y equipamiento urbano (ver Salinas, 2016). La "gentrificación positiva" ha quitado la esencia crítica del concepto, para ser usado en las políticas públicas. Con esto se desarrolla la gentrificación de la teoría (Smith, 1996).

Por lo tanto, la gentrificación entendida como una reestructuración de clase y de relaciones sociales en el espacio (Salinas, 2015), como una postura crítica, deberá considerar a las transformaciones urbanas como un problema social o de clase, en donde la inversión de capital revaloriza el espacio urbano, lo que genera espacios destinados para población de ingresos medios y altos generando desplazamiento de un sector de la población de bajos recursos económicos. La gentrificación como un mecanismo de reestructuración de clase está generando espacios para la reproducción de capital y consumo de clases altas.

\section{Discusiones sobre gentrificación en América Latina}

En ciudades de los países latinoamericanos las características de los procesos de gentrificación se diferencian de los ocurridos en otras latitudes. De igual manera, se aprecian diferencias entre ciudades de cada país latinoamericano, así como dentro de una misma ciudad. Siguiendo los argumentos de Janoschka, Sequera y Salinas (2013), en el cual realizan una revisión sobre las perspectivas de los estudios de la gentrificación en diversos casos de estudio de ciudades latinoamericanas, se pueden mencionar tres mecanismos que caracterizan los procesos de gentrificación. Estos mecanismos se encuentran estrechamente relacionados, en donde las transformaciones urbanas muestran diversas aristas que podrán encajar en cada uno de ellos. 
a) Gentrificación simbólica - transformaciones sociales en la imagen urbana

Los centros históricos y áreas centrales de las ciudades de América Latina se han caracterizado por la ocupación del espacio público por parte de población de escasos recursos económicos, destacando población indígena, vendedores ambulantes y, en general, del comercio informal, además de población que vive en la calle. Esta situación, para los gobiernos locales, representa obstáculos para la atracción de inversión privada así como para la visita de turistas, tanto nacionales como extranjeros. De manera que es considerado como uno de los principales problemas de la imagen urbana.

Por lo anterior, se han desarrollado medidas cuyo objetivo es la "recuperación urbana"; recuperación en el sentido que plantea Smith (1996) sobre la ciudad revanchista, es decir, sobre la reconquista simbólica de un espacio central por parte de clases medias que lo habían perdido (con la expansión urbana al salirse de los centros históricos y áreas centrales). De manera que es común observar el reforzamiento de la seguridad pública, mejorar el alumbrado público, mantenimiento de los espacios públicos como parques y plazas y desplazar a población dedicada al comercio informal y, en algunos casos, no sólo a vendedores ambulantes, sino además a mendigos y niños de la calle, en cuya gran proporción están conformados por población proveniente de zonas rurales, muchos de los cuales son población indígena, tal como se demuestra para los casos de estudio sobre Quito y Guayaquil, Ecuador (Swanson, 2007) y en la Ciudad de México (Crossa, 2009; Moctezuma, 2016).

\section{b) Políticas neoliberales de gentrificación - patrimonio histórico}

En muchas de las ciudades latinoamericanas, cuya riqueza del patrimonio histórico ha hecho que algunos centros históricos estén inscritos en la lista del Patrimonio Mundial de la UNESCO, ha promovido su mantenimiento por parte de los gobiernos nacionales y locales. Dicha situación, a partir de diversas políticas plasmadas en planes y programas de "recuperación" o "rescate" del patrimonio histórico, se han manejado como "marketing urbano", en el cual se busca generar espacios atractivos para el turismo y la inversión extranjera, tal como se argumenta para los casos de Cuenca, Ecuador y Cusco, Perú (Steel y Klaufus, 2010), Buenos Aires, Argentina (Gómez y Zunino, 2008), Santamarta, Colombia (Ospina, 2009), Porto Alegre y Salvador, Brasil (Sanfelici, 2007; Nobre, 2003, respectivamente). De esta manera, mencionan Bromley y Mackie, el centro de una ciudad, cuyo valor histórico patrimonial se destina al turismo puede ser más propenso a experimentar gentrificación (Bromley y Mackie, 2009, p.4).

Si bien es cierto, esto está sucediendo en grandes ciudades con importante riqueza patrimonial, no exime de transformaciones en ciudades medias y pequeñas, así como en algunas localidades que presentan diversas cualidades rurales y una fuerte dinámica económica y turística con ciudades medias y grandes cercanas. Como ejemplo de una política neoliberal de gentrificación para el caso de México está el programa federal "Pueblos Mágicos" definido por el propio gobierno federal como "Localidades con atributos simbólicos, leyendas, historia, hechos trascendentes, cotidianidad, magia que te emanan en cada una de sus manifestaciones socio-culturales, y que significan hoy día una gran oportunidad para el aprovechamiento turístico." (Secretaría de Turismo). Hasta el año 2016 existen 111 Pueblos Mágicos. La función del gobierno federal es otorgar subsidios a las entidades federativas con el objetivo de diversificar y mejorar la calidad de estos destinos, productos y servicios turísticos, así como estimular y fomentar la inversión pública y privada. Lo que ha sucedido con estos pueblos es una importante transformación en el uso funcional de viviendas, sustituidas por usos no residenciales y alojamientos turísticos tales como hoteles, restaurantes, bares, discotecas, agencias de viajes, boutiques, galerías, etcétera. Muchos de estos espacios son ocupados por jubilados extranjeros, principalmente estadounidenses y canadienses, desplazando a la población originaria. Estos cambios son parte del proceso de gentrificación que se produce en pueblos y localidades mexicanas.

Otra política neoliberal de gentrificación es la estrecha vinculación entre las autoridades locales y el sector privado. Un ejemplo para el caso de la Ciudad de México es la 
constitución de la empresa paraestatal PROCDMX (Agencia de Promoción, Inversión y Desarrollo para la Ciudad de México), la cual realiza funciones de una consultora de la ciudad, proponiendo espacios urbanos para realizar proyectos de inversión. Es la encargada de realizar un inventario de espacios "subutilizados" que con inversión privada podrían transformar y reproducir capital.

\section{c) Nuevos mercados inmobiliarios - Inversión privada en centro y periferia}

La gestión urbana se ha encargado de estimular la inversión privada, tanto en las áreas centrales como en la periferia de las ciudades Latinoamericanas. Algunas de las intervenciones directas se concretan en extensión de impuestos, tales como derechos de construcción, reducción de pagos de avisos y permisos de obra (para el caso de Buenos Aires ver; Rodríguez, Bañuelos y Mera, 200, p.82), estímulos a la oferta y demanda, (como sucede con el Programa de Repoblamiento Habitacional en Santiago de Chile), cambios de uso de suelo, hasta nuevas modalidades de ocupación del suelo, como acontece con el "Proyecto Puerto Maravilla" en Río de Janeiro (Lima, 2010) 0 con las obras de la ribera, realizadas en el sur de la ciudad de Buenos Aires (Lanzetta y Martín, 2001; Rodríguez, Bañuelos y Mera, 2008).

Si bien es cierto, muchas intervenciones inmobiliarias, tanto para vivienda, comercio y oficinas son localizadas en las áreas centrales, también es cierto que la configuración policéntrica de las grandes ciudades está inyectando capital en diversas zonas de las ciudad. Un elemento a destacar, es la creciente aparición de fraccionamientos cerrados dirigidos a población de ingresos medios y altos, los cuales, construidos en un contexto de propagación del discurso del miedo, surgen como espacios deseados, cuya mayor cualidad son las estrategias de securitización, las cuales no se limitan a estrategias de prevención del delito y reforzamiento de la seguridad, sino van más allá, al grado de influir o determinar las prácticas de comportamiento, estableciendo usos y costumbres que corresponden a prácticas de diferenciación socioespacial.

\section{Conclusiones}

Desde sus orígenes, el concepto de gentrificación hace referencia a una problemática social o de clase. Es la connotación crítica del concepto, frente a la producción del espacio urbano por y para un sector de la población de altos ingresos.

Lo que ha variado del concepto, a más de 50 años de su aparición, no debería de ser la connotación de clase, además de la llegada de población de mayores ingresos, inversión de capital y desplazamiento de población. Sino únicamente lo referente al uso del suelo. Es decir, se origina con las transformaciones en el uso habitacional, sin embargo, la lucha de clases se materializa en el espacio urbano en otros usos de suelo, tales como el comercial o productivo. Tanto la gentrificación comercial como productiva hace referencia a inversión de capital, desplazamiento (comerciantes y trabajadores) y llegada de población de mayor capacidad de consumo.

Estas características del proceso de gentrificación se presentan en ciudades de América Latina, de manera particular, en las transformaciones sociales en la imagen urbana, llamada como gentrificación simbólica, la implementación de políticas neoliberales de gentrificación sobre el patrimonio histórico y áreas diversas del espacio urbano, y con nuevos mercados inmobiliarios, inversión privada tanto en el centro como en la periferia.

Para concluir, se ha mencionado cierta escasez de trabajos sobre gentrificación en América Latina, en comparación con la gran cantidad de trabajos anglosajones, pero recientemente se aprecia un creciente interés sobre el tema. Esto se evidencia a partir de que la mayoría de las publicaciones al respecto son generadas en la última década, lo cual sugiere necesario la producción de trabajos empíricos cuya caracterización en ciudades latinoamericanas contribuya a enriquecer la discusión sobre el proceso de gentrificación, sin perder la perspectiva crítica del concepto. 


\section{Referencias Bibliográficas}

Boixader, J. (2004). "Nuevas tecnologías y reno- vación urbana: luces y sombras del distrito 22@ Barcelona", Scripta Nova: Revista elec- trónica de Ciencias Sociales, vol. 8, No 170 (34). Disponible en internet: http://www. ub.edu/geocrit/sn/sn-17034.htm.

Bridge, Gary y Dowling, Robyn. (2001). "Microgeographies of retailing and gentrification”, Australian Geographer. 32(1): 93-107.

Bromley, R. y Mackie, P. (2009). "Displacement and the New Spaces for Informal Trade in the Latin American City Centre", Urban Studies, vol. 46(7), pp. 1485-1506.

Crossa, V. (2009). "Resisting the Entrepreneurial City: Street Vendors' Struggle in Mexico City's Historic Center", International Journal of Urban and Regional Research, vol. 33.1, marzo, Oxford: Blackwell Publishing. pp.43-63.

Delgadillo, V. (2013). "América Latina urbana: la construcción de un pensamiento teórico propio Entrevista con Emilio Pradilla Cobos", Andamios, Revista de Investigación Social. UACM, vol. 10, número 22, pp. 185-201.

Dot, E.; Casellas, A. y Pallares-Bar, M. (2010). "Gentrificación productiva en Barcelona: efectos del nuevo espacio económico", Actas de la IV Jornada de Geografía Económica, Disponible en Internet: http://age.ieg.csic.es/geconomica/ IVJornadasGGELeon/ Comunicaciones\%20Jornadas\%20de\%20 Leon/1\%20 Ponencia/Dot-Casellas-Pallar.pdf.

Florida, R. (2010). La clase creativa. La transformación de la cultura del trabajo y el ocio en el siglo XXI. Madrid: Paidós.

García, L. (2001). "Elitización: propuesta en español para el término gentrificación", en Scripta Nova. Revista electrónica de geografía y ciencias sociales. Barcelona: Universidad Barcelona, vol. VI, núm 332.

Gómez, M. y Zunino, D. (2008). "La (re)valorización de la zona sur y su patrimonio histórico - cultural como recurso turístico", en: Herzer, H., (Org.), Con el corazón mirando al sur. Transformaciones en el sur de la ciudad de Buenos Aires. Buenos Aires: ed. Espacio.

González, S. y Waley, P. (2012). "Traditional Retail Markets: The New Gentrfication Frontier?" Antipode: a radical journal of geography. 45(4): 965-983.

Guillamón, I. (2003) “¿Del Manchester Catalán al Soho Barcelonés? La renovación del barrio de PobleNou en Barcelona y la cuestión de la vivienda", Scripta Nova. Revista Electrónica de Geografía y Ciencias Sociales, Vol. 8, No 146 (137).

Hamnett, C. (1991). "The blind men and the elephant: the explanation of gentrification", Transactions of the Institute of British Geographers, New Series. vol. 16, núm. 2, London: Royal Geographical Society. pp. 173-189.

Herzer, H. (2008). Con el corazón mirando al sur. Transformaciones en el sur de la ciudad de Buenos Aires. Buenos Aires: ed. Espacio.

Janoschka, M., Sequera J. y Salinas L. (2013). "Gentrification in Spain and Latin America - a Critical Dialogue", International Journal of Urban and Regional Research, vol. $38, N^{\circ} 4.1234-1265$.

Jaramillo, S. (2006). "Reflexiones sobre las políticas de recuperación del centro (y del centro histórico) de Bogotá", Documento CEDE, No 2006-40, Universidad de los Andes, Bogotá.

Lanzetta, M., y Martín, L. (2001). "El proceso de renovación urbana en el barrio de La Boca (Buenos Aires). Vulnerabilidad y organización social”, en Latin American Studies Association Meeting, Washington DC, September 6-8.

Lees, L., Slater, T. y Wyly, E. (2008). Gentrification. New York: Routledge.

Ley, D. (1978). "Inner city resurgence units societal context", Conferencia Anual de la Asociación de geógrafos americanos, Nueva Orleans. 
Ley, D. (1980). "Liberal ideology and the postindustrial city", en Annals of the association of american geographers, vol. 70, núm. 2, pp. 238-258.

Ley, D. (1994). "Gentrification and the politics of the new middle class", en Environment and Planning D: Society and Space, vol. 12, pp. 53-74.

Ley, D. (2003). "Artists, Aestheticisation and the Field of Gentrification", en Urban Studies, vol. 40, núm. 12, november, pp. 2527-2544.

Lima, C. (2010). "Una mirada crítica a la zona portuaria de Río de Janeiro", en Bitácora17 vol. 2, Bogota: Universidad Nacional de Colombia. pp. 23 - 54.

Moctezuma,V. (2016). "El desplazamiento de lo posible: experiencia popular y gentrificación en el Centro Histórico de Ciudad de México", Íconos. Revista de Ciencias Sociales. Num. 56, pp. 83-102.

Nobre, E. (2003). "Intervençães urbanas em Salvador: turismo e "gentrificação no processo de renovação urbana do Pelourinho". Artículo en línea disponible en http://www.usp.br/fau/docentes/depprojeto/e_nobre/intervencoes_urbanas_ Salvador.pdf.

Ospina, N. (2009). "Análisis sobre la Recuperación del Centro Histórico de Santa Marta, Colombia: Entre el discurso turístico y las problemáticas sociales". Artículo en línea disponible en http://www.ram2009.unsam.edu.ar/GT/GT\%2050\%20-\%20 Ciudad,\%20 Cultura\%20y\%20Procesos\%20de\%20Segregación\%20Urbana/ GT50\%20-\%20Ponencia\% 20[Ospina].pdf.

Rérat, P., Söderström, O. y Piguet, E. (2010). "New Forms of Gentrification: Issues and Debates", en Population, Space Place. vol. 16, pp. 335-343.

Rodríguez, C., Bañuelos, C. y Mera, G. (2008). “Intervención-no intervención: ciudad y políticas públicas en el proceso de renovación del Área Sur de la Ciudad de Buenos Aires", en: Herzer, H. (org.), Con el corazón mirando al sur. Transformaciones en el sur de la ciudad de Buenos Aires. Buenos Aires: Espacio Editorial.

Romero, L. y Lara, L. (2015). "De barrio-problema a barrio de moda: gentrificación comercial en Russafa, El "Soho" valenciano", Anales de Geografía de la Universidad Complutense. 35(1): 187-212.

Sabatini, F., Sarella, M. y Vásquez, H. (2008) "Gentrificación sin expulsión, o la ciudad latinoamericana en una encrucijada histórica" Revista_180, 24, p. 18-25.

Salinas, L. (2015). "Transformación de mercados municipales de Madrid. De espacio de consumo a espacio de esparcimiento", Revista INVI, No 85, Vol. 31, pp. 179 - 201, Santiago de Chile.

Salinas, L. (2016). "Política de vivienda en la Zona Metropolitana del Valle de México: entre la gentrificación y la segregación", Estudios Geográficos, CSIC, vol. 77, núm. 280 , pp. $357-365$.

Sanfelici, D. (2007). "Urbanismo neoliberal e gentrificação: as políticas de revitalização do centro de Porto Alegre/RS", en Ciênc. let., n.41, jan./jun. Porto Alegre, pp. 188203.

Slater, T. (2006). "The Eviction of Critical Perspectives from Gentrification Research", en International Journal of Urban and Regional Research. vol. 30.4, december, Oxford: Blackwell Publishing. pp. 737-757.

Slater, T. (2008). "'A Literal Necessity to be Re-Placed': A Rejoinder to the Gentrification Debate.", en International Journal of Urban and Regional Research. vol. 32.1, march, Oxford: Blackwell Publishing. pp. 212-223.

Smith, N. (1979). Toward a theory of gentrification: a back to the city movement by capital, not by people. Journal of the American Planning Association, 45, p.38-548.

Smith, N. (1996). The New Urban Frontier. Gentrification and the revanchist city. Londres: Routledge.

Steel, G. y Klaufus, C. (2010). "Displacement by/for development in two Andean cities". Artículo en línea disponible en http://lasa.international.pitt.edu/members/ congress-papers/lasa2010/files/1998.pdf. 
Swanson, K. (2007). "Revanchist Urbanism Heads South: The Regulation of Indigenous Beggars and Street Vendors in Ecuador", en Antipode, vol. 39(4), pp. 708-728.

Van Weesep, J. (1994). "Gentrification as a research frontier", en Progress in Human Geography, vol. 18. núm. 1, pp. 74-83.

Zukin, S. (1987). "Gentrification: Culture and Capital in the Urban Core", en Annual Review of Sociology, Vol. 13, pp. 129-147. 